\title{
FAKTOR-FAKTOR YANG MEMPENGARUHI MINAT PEGAWAI NEGERI SIPIL UNTUK MELAKUKAN TINDAKAN WHISTLEBLOWING
}

\author{
Refaoni Aida ${ }^{1}$, Herlina Helmy ${ }^{2}$, Mia Angelina Setiawan ${ }^{3}$ \\ ${ }^{1}$ Alumni Jurusan Akuntansi Fakultas Ekonomi, Universitas Negeri Padang \\ ${ }^{2}$ Jurusan Akuntansi Fakultas Ekonomi, Universitas Negeri Padang \\ ${ }^{3}$ Jurusan Akuntansi Fakultas Ekonomi, Universitas Negeri Padang \\ *Korespodensi: refaoniaidaa@gmail.com
}

\begin{abstract}
This study aims to examine the influence of organizational commitment, seriousness of wrongdoing, personal cost and attitude on the whistleblowing intentions among civil servant in the Padang State University. This research used primary data collected from questionnaire survey. Using a sample of 146 respondents, this research show that two determinants significantly affect whistleblowing intention. The two affecting determinants are organizational commitment and seriousness of wrongdoing, and the two not affecting are personal cost and attitude on the whistleblowing intention. The first variable is organizational commitment has significant positive effect on the whistleblowing intentions, where the tcount 3,058> ttable 1,97693at sig0,000 < 0,05. The second variable is seriousness of wrongdoing has significant positive effect on the whistleblowing intentions, where the tcount 3.347>ttable 1,97693 at sig $0,001<\alpha 0,05$. The third variable is personal cost has not significant positive effect on the whistleblowing intentions, where the tcount 0,573 < ttable1,97693 at sig 0,568 > 0,05. The last variable is attitude has not significant positive effect om the whistleblowing intentions, where the tcount 0,467 < ttable1,97693 at sig 0,641 > 0,05.
\end{abstract}

Keywords: Organizational Commitment; Seriousness of Wrongdoing; Personal Cost and Attitude; Whistleblowing.

How to cite (APA $6^{\text {th }}$ style)

Aida, Revaoni., Helmy, Herlina \& Angelina Setiawan, Mia. (2019). Faktor-Faktor yang Mempengaruhi Minat Pegawai Negeri Sipil untuk Melakukan Tindakan Wistlebowing. Jurnal Eksplorasi Akuntansi, 1(4), Seri A, 1633-1649.

\section{PENDAHULUAN}

Association of Certified Fraud Examination (ACFE) menyebutkan adanya kecurangan dalam akuntansi yang dapat dikategorikan menjadi tiga kelompok yaitu kecurangan dalam laporan keuangan, penyalahgunaan aset dan korupsi. Pada pemerintah dan sektor administrasi memiliki proporsi kasus kecurangan dan korupsi yang tinggi diperingkat ketiga sebesar 50\%. Berdasarkanreport tersebut, fraud atau kecurangan yang terjadi tentu saja harus ditindak lanjuti dan menjadi tanggung jawab setiap orang yang terlibat dalam pemerintahan tersebut. Oleh sebab itu, diperlukan suatu tindakan untuk mengungkapkan kesalahan atau kecurangan yang ada di pemerintahan. Salah satu tindakan yang bisa dilakukan adalah whistleblowing. 
Fraud memiliki faktor penyebab terjadinya kecurangan dan tidak terlepas dari konsep fraud diamond. Ada empat penyebab terjadinya kecurangan yaitu tekanan (pressure), tekanan dapat diakibatkan oleh berbagai hal termasuk tekanan yang bersifat finansial dan non finansial. Penyebab kedua kecurangan adalah kesempatan, kesempatan terjadi karena kurang efektifnya pengendalian internal, manajemen pengawasan yang kurang memadai serta prosedur yang tidak jelas ikut andil dalam membuka peluang.

Pemerintahan sebagai organisasi bekerja dengan tugas menjalankan suatu sistem pemerintahan. Suatu sistem pemerintahan yang baik tidak akan pernah lepas dengan masalah fraud yang terjadi dalam internal maupun eksternal pemerintahan tersebut. Fraud atau kecurangan adalah serangkaian tindakan tidak wajar dan ilegal yang sengaja dilakukan untuk menipu, kecurangan dilakukan oleh individu atau organisasi untuk mendapatkan uang. Wells (2007) mendefinisikan fraud sebagai "criminal deception intended to financially benefit the deceifer", yaitu penipuan kriminal yang bermaksud untuk memberi manfaat keuangan kepada si penipu.

Penyebab ketiga kecurangan yaitu rasionalisasi. Rasionalisasi yang terjadi karena sikap pembenaran yang dilakukan oleh pelaku dengan merasionalkan bahwa tindakan kecurangan adalah sesuatu yang wajar. Para pelaku fraud biasanya mencari berbagai alasan secara rasional untuk menjustifikasikan tindakan mereka. Penyebab kecurangan terakir yaitu individual capability, individual capability adalah sifat dan kemampuan pribadi seseorang yang mempunyai peranan besar yang memungkinkan melakukan suatu tindakan kecurangan.

Whistleblowing merupakan langkah yang tepat untuk mencegah terjadinya kasus pelanggaran-pelanggaran akuntansi serta menjadi ukuran kunci dalam pertempuran melawan penipuan dan korupsi. Terbukti pengaduan tindakan whistleblowing lebih efektif dalam mengungkapkan fraud dibandingkan metode lainnya seperti audit internal, pengendalian internal maupun audit eksternal (Rizki, 2014). Beberapa bukti whistleblowing lebih efektif dalam mengungkapkan korupsi dan kecurangan bisa diliat dari salah satu kasus yang melibatkan whistleblower yang terjadi di Indonesia yaitu kasus Susno Duaji yang mengungkapkan adanya mafia pajak di instansinya yang melibatkan Gayus Tambunan seorang staf Direktorat Jenderal Pajak terkait dengan kasus pencucian uang dan korupsi.

Near et al., (1993) yang dikutip oleh Rizki (2014) menyatakan bahwa kekuatan dari whistleblowing ini bergantung pada whistleblower, partisipasiwhistleblower krusial terhadap efektifitas tindakan whistleblowing. Namun meskipun begitu menjadi seorang whistleblower tidaklah mudah karena akan menerima banyak tantangan dari internal maupun eksternal lingkup kerjanya.

Pentingnya pemahaman tentang whistleblowing dalam mengungkapkan adanya tindakan fraud (Dycket al dalam Humaira, 2017), dapat menumbuhkan minat seorang untuk melakukan whistleblowing. Secara khusus seorang PNS memungkinkan untuk menjadi whistleblower karena PNS merupakan sumber daya yang paling dekat dengan setiap tindakan kecurangan dan berada dalam posisi terbaik untuk menjumpai praktik ilegal dalam organisasi sehingga proses penyidikan dapat segera dimulai ketika mereka menyediakan informasi yang relevan dan handal.

Minat seseorang untuk melakukan tindakan whistleblowing dapat dilihat melalui faktorfaktor yang mempengaruhinya. Diantaranya yaitu komitmen organisasi, tingkat keseriusan kecurangan, personal cost dan sikap. Sejalan dengan penelitian Rizki (2014) yang menguji ke empat determinan tersebut dengan responden PNS pada BPK RI. Penelitian sebelumnya dilakukan oleh Indri (2016) dan Resi (2017) telah meneliti beberapa faktor yang memiliki 
kesamaan determinan yang dapat mempengaruhi whistleblowing. Diantaranya personal cost, komitmen professional, dan tingkat keseriusan kecurangan.

Banyaknya penelitian tentang whistleblowing, namun masih minim dilakukan disektor publik khususnya pada lingkup perguruan tinggi negeri yang berstatus badan layanan umum. Penelitian ini menguji faktor komitmen organisasi, tingkat keseriusan kecurangan, personal cost dan sikap terhadap responden pada PNS dilingkup perguruan tinggi negeri. Berdasarakan uraian tersebut, maka peneliti mengambil judul "Faktor-faktor Yang Mempengaruhi Minat Pegawai Negeri Sipil Untuk Melakukan Tindakan Whistleblowing”.

\section{REVIEU LITERATUR DAN HIPOTESIS PENELITIAN Theory of Planned Behavior (TPB)}

Salah satu teori yang mendukung whistleblowing adalah theory of planned behavior. Menurut Ajzen (1991), ia mengemukakan bahwa sikap dan perilaku itu saling berhubungan. Teori ini timbul sebagai jawaban atas kegagalan determinan sikap (attitude) dalam memprediksi tindakan/perilaku aktual (actualbehavior) secara langsung. TPB membuktikan bahwa minat (intention) lebih akurat dalam memprediksi perilaku aktual dan sekaligus dapat sebagai proxy yang menghubungkan antara sikap dan perilaku aktual. Teori Ajzen (1991) tersebut telah diterima secara luas sebagai alat untuk menganalisis perbedaaan antara sikap dan minat serta perilaku pada berbagai penelitian yang berusaha menjelaskan serta memprediksi perilaku objek penelitian sebagai hasil proses psikologi yang kompleks. Oleh karena itu, berdasarkan TPB tersebut minat dijadikan sebagai faktor untuk memprediksi tidakan whistleblowing seseorang.

\section{Whistleblowing}

Bouvilee (2007) mendefenisikan whistleblowing sebagai tindakan, dari seorang pegawai (atau mantan pegawai), untuk mengungkapkan apayang ia percaya sebagai perilaku ilegal atau tidak etis kepada manajemen yang lebih tinggi/manajemen puncak (internal whistleblowing) atau kepada otoritas/pihak berwenang diluar organisasi maupun kepada publik (external whistleblowing).

Tindakan whistleblowing dilakukan guna untuk mengungkapkan kecurangan yang terjadi dalam suatu organisasi atau perusahaan dan sangat diperlukan agar dapat menciptakan Good Corporate Governanceyang baik. Namun pengungkapan kecurangan pada umunya menimbulkan konsekuensi yang tidak diinginkan oleh si pengungkap kecurangan (whistleblower) tersebut, seperti kehilangan pekerjaan, balas dendam, dan isolasi dalam bekerja). Karena itu untuk menjadi whistleblower tidaklah mudah karena pihak whistleblowerakan menghadapi dilemma etis antara harus "meniup pluit" atau membiarkan kecurangan tersebut tetap tersembunyi (Bagustianto, 2014).

\section{Komitmen Organisasi}

Menurut Curtis (2010) komitmen organisasi didefinisikan sebagai arah kesetiaan seseorang ditujukan ketika mengalami dilema antara komitmen organisasi dengan komitmen rekan kerja yang saling bertentangan satu sama lain. Mowday et al (1979) mendefinisikan komitmen organisasi sebagai kekuatan relatif identifikasi dan keterlibatan individu dalam organisasi tertentu yang dapat ditandai dengan tiga faktor terkait yaitu; pertama, keyakinan yang kuat dan penerimaan terhadap tujuan dan nilai-nilai organisasi; kedua, kesediaan untuk mengerahkan usaha yang cukup atas nama organisasi; dan terakir, keinginan yang kuat untuk mempertahankan keanggotaan dalam organisasi (loyalitas). 


\section{Tingkat Keseriusan Kecurangan}

Winardi (2013) menyatakan bahwa organisasi akan terkena dampak kerugian yang lebih besar dari wrongdoing yang lebih serius dibandingkan dari wrongdoing yang kurang serius. Para pegawai, sebagai bagian organisasi, akan merasa bahwa mereka memiliki tanggung jawab melindungi tempat kerjanya dari kerugian dan bahaya. Tingkat keseriusan kecurangan merupakan faktor pertama untuk menilai apakah whistleblowing yang dilakukan sudah adil. Tingkat keseriusan kecurangan mungkin akan membuat perbedaan pendapat dari sikap orang yang akan melaporkan kecurangan. Jadi, tingkat keseriusan kecurangan harus diperhatikan dengan seksama, karena secara tidak langsung tingkat keseriusan kecurangan dapat menjadi satu faktor penting.

\section{Personal Cost}

Personal cost adalah pandangan pegawai terhadap risiko pembalasan/balas dendam atau sanksi dari anggota organisasi, yang dapat mengurangi minat pegawai untuk melaporkan wrongdoing (Schutlz et al., 1993 dalam Rizki, 2014). Sabang (2013) juga menambahkan bahwa personal cost bukan hanya dampak tindakan balas dendam dari pelaku kecurangan, melainkan juga keputusan menjadi pelapor dianggap sebagai tindakan tidak ertis, misalnya melaporkan kecurangan atasan dianggap sebagai tindakan yang tidak etis karena menentang atasan.

Personal cost menjadi pemikiran yang paling utama sebelum seseorang melakukan pelaporan (whistleblowing), karena personal cost menjadi bahan pertimbangan yang sangat berpengaruh bagi pihak yang akan melaporkan kecurangan. Apalagi jika tindakan pelaporan yang akan dilakukan akan membahayakan posisinya sehingga itu akan membuat kecendrungan pelaporan menjadi minim. Menurut Curtis (2006) dalam Alleyne (2012) indikator personal cost berupa pembalasan yang mungkin datang dalam bentuk penolakan kenaikan gaji, penilaian kinerja yang tidak adil, kurangnya dukungan rekan (misalnya pengucilan), transfer ke tempat atau pekerjaan yang tidak inginkan, dan kemungkinan ketakutan.

\section{Sikap}

Gibson (2012) mendefinisikan sikap sebagai perasaan positif atau negatif atau keadaan mental yang selalu disiapkan, dipelajari, dan diatur melalui pengalaman, yang memberikan pengaruh khusus pada respon seseorang terhadap orang, obyek-obyek atau keadaan. Dalam kaitannya dengan theory of planned behavior, Park dan Blenkisopp (2009) mendefinisikan sikap sebagai penilaian seorang individu atas seberapa setuju atau tidak setujunya individu tersebut terhadap suatu perilaku/tindakan tertentu.

\section{Pengaruh Komitmen Organisasi terhadap Minat Melakukan Whistleblowing}

Komitmen terhadap organisasi merupakan salah satu faktor penting yang harus diperhatikan dalam penelitian di tempat kerja. Seseorang akan memiliki tingkat komitmen yang tinggi terhadap perusahaannya apabila ia bersedia untuk bekerja penuh pada perusahaan, menjaga asetaset perusahaan, berusaha untuk mewujudkan tujuan perusahaan. Penelitian terdahulu membuktikan bahwa komitmen organisasi tidak memiliki pengaruh terhadap niat melakukan whistleblowing. Komitmen organisasi tidak memiliki korelasi atau keterkaitan dengan minat whistleblowing. Berbeda dengan hasil penelitian Rizki (2014) dan Rohmaida (2017) yang menyimpulkan bahwa komitmen organisasi berpengaruh signifikan positif terhadap minat PNS untuk melakukan tindakan whistleblowing. 
Pertimbangan penggunaan faktor komitmen organisasi PNS terhadap minat untuk melakukan tindakan whistleblowing akan coba diuji kestabilan pengaruhnya dalam penelitian ini karena komitmen organisasi dan tindakan whistleblowing berkaitan/sejalan dengan prosocial organizational behavior theory. Pegawai yang memiliki komitmen organisasi yang tinggi seharusnya akan loyal, peduli pada organisasi, siap membela organisasinya dan tidak ragu untuk mengungkap dugaan kecurangan (tindakan whistleblowing) yang terjadi demi melindungi organisasi tersebut. Maka berdasarkan penjelasan diatas kesimpulan hipotesis yang dapat ditarik yaitu:

H1: Komitmen organisasi berpengaruh positif terhadap minat pegawai negeri sipil melakukan tindakan whistleblowing

\section{Pengaruh Tingkat Keseriusan Kecurangan terhadap Minat Melakukan Whistleblowing}

Menurut Winardi (2013) seseorang akan mempertimbangkan akibat yang ditimbulkan dari suatu kecurangan sebelum melakukan tindakan atas kecurangan tersebut. Tingkat keseriusan kecurangan dapat berupa persepsi bagaimana seseorang menaruh tingkatan tentang permasalahan.Juga tentang bagaimana seseorang memandang dampak negatif yang mungkin ditimbulkan oleh masalah yang terjadi.

Terdapat dua kemungkinan arah hubungan tingkat keseeriusan kecurangan terhadapa minat whistleblowing, yaitu:

a. Berpengaruh positif. Semakin besar nilai atau dampak kecurangan yang diketahui maka semakin besar rasa tanggungjawab anggota organisasi untuk mengungkapkannya atau sebaliknya.

b. Berpengaruh negatif. Tingkat kecurangan yang selalu signifikan dapat memperbesar risiko whistleblowing, sehingga perilaku whistleblower dapat menjadi lebih konservatif dan semakin menghindari untuk bertindak agresif dalam mengungkapkannya.

Dari penjelasan diatas, pengaruh positif lebih dominan dari pada pengaruh negatif terhadap tingkat keseruisan kecurangan.Sejalan dengan penelitian yang dilakukan Rizki (2014), Winardi (2013), Indri (2016) yang menemukan pengaruh signifikan antara tingkat keseriusan masalah dengan tingkat terjadinya whistleblowing. Maka dapat ditarik hipotesis sebagai berikut.

H2: Tingkat keseriusan kecurangan berpengaruh positif terhadap minat PNS melakukan tindakan whistleblowing.

\section{Pengaruh Personal Cost terhadap Minat Melakukan Whistleblowing}

Personal cost atau biaya pribadi pelaporan merupakan dampak atau bisa disebut balas dendam yang akan diterima jika seseorang melakukan atau kecurangan yang dilakukan oleh orang lain. Biaya pribadi yang akan diterima pelapor akan memperkuat atau justru membuat orang tersebut enggan untuk melakukan pelaporan. Jika dampak yang timbul dari pelaporan yang dilakukan besar, tentu saja akan mengurangi keinginan seseorang untuk melakukan pelaporan. Seseorang tentu saja lebih ingin melindungi dirinya sendiri.

Jadi seseorang akan cenderung melakukan pelaporan (whistleblowing) jika efek yang diterimanya kecil. Mereka tentu saja akan memikirkan kemungkinan pegucilan untuk dirinya atau efek lain yang mungkin saja bisa diterimanya saat ia melakukan pelaporan. Jika dia berpikir bahwa efek yang akan diterimanya besar, mungkin orang tersebut akan berpikir untuk melakukan pelaporan atau mereka akan lebih menarik diri dengan berpura-pura tidak menyadari kecurangan tersebut. Peneliti tedahulu yang dilakukan Rizki (2014) dan Indri (2016) bahwa tindakan atau minat melakukan whistleblowing dipengaruhi oleh persepsi tentang seberapa besar 
personal cost dianggap berpengaruh signifikan negatif dengan tindakan whistleblowing. Sehingga dapat ditarik hipotesis sebagai berikut

H3: Personal Cost berpengaruh negatif terhadap minat PNS melakukan tindakan whistleblowing.

\section{Pengaruh Sikap terhadap Minat Melakukan Whistleblowing}

Sikap merupakan keadaan dalam diri manusia yang berupa perasaan maupun respon untuk mendukung atau memihak maupun tidak mendukung pada suatu objek. Sikap terhadap whistleblowing menurut Park dan Blenkinsopp (2009) mengenai sejauh mana individu memiliki evaluasi menguntungkan atau tidak menguntungkan dari whistleblowing adalah jumlah keyakinan yang dimiliki karyawan tentang konsekuensi tersebut. Dengan begitu, seseorang untuk dapat menjadi whistleblower harus memiliki komponen keyakinan bahwa whistleblowing adalah tindakan yang memiliki konsekuensi positif. Keyakinan konsekuensi positif tersebut dievaluasi oleeh sistem nilai individu seseorang dan menghasilkan sikap, sikap positif yang mampu mendorong kecendrungan seseorang untuk melakukan whistleblowing.Sehingga, semakin besar kecendrungan sikap positif seseorang untuk melakukan whistleblowing.

Park dan Blenkinsopp (2009) menemukan bahwa sikap petugas kepolisian terhadap whistleblowing memiliki efek positif terhadap niat whistleblowing. Winardi (2013) dan Ilham (2016) juga menambahkan sikap berpengaruh signifikan positif terhadap niat melakukan tindakan whistleblowing. Berdasarkan penjelasan diatas, maka hipotesis pertama penelitian ini adalah:

H4: Sikap terhadap whistleblowing bepengaruh positif terhadap minat melakukan tindakan whistleblowing.

\section{METODE PENELITIAN}

Jenis Penelitian

Jenis penelitian ini menggunakan pendekatan kuantitatif yang bertujuan untuk melihat seberapa jauh variabel independen mempengaruhi variabel dependen. Variabel independen diantaranya adalah komitmen organisasi, tingkat keseriusan kecurangan, personal cost, dan sikap. Sedangkan variabel dependen adalah minat melakukan whistleblowing.

\section{Populasi dan Sampel}

Populasi pada penelitian ini adalah seluruh tenaga kependidikan dan dosen PNS golongan II, III, IV dilingkup Universitas Negeri Padang yang berjumlah 1592 orang pegawai dengan rincian 366 orang tenaga kependidikan dan 1226 orang.Sampel dalam penelitian ini ditentukan berdasarkan golongan (cluster) dengan menggunakan rumus slovin sehingga responden yang didapat berjumlah 319 orang. 


\section{Teknik Pengumpulan Data}

Teknik pengumpulan data yang digunakan dalam penelitian ini adalah teknik kuesioner atau angket. Teknik kuesioner atau angket ini digunakan dengan menyebarkan kuesioner di tempat penelitian dan pengembalian kuesioner dijemput langsung ketempat penelitian.

\section{Variabel Penelitian}

Variabel dependen dalam penelitian ini adalah niat melakukan whistleblowing, sedangkan variabel independen dalam penelitian ini adalah komitmen organisasi, tingkat keseriusan kecurangan, personal cost, dan sikap.

\section{Teknik Analisis Data}

Penelitian ini menggunakan model analisis regresi berganda untuk menganalisis pengaruh komitmen organisasi, tingkat keseriusan kecurangan, personal cost, dan sikap terhadap minat melakukan whistleblowing dengan model sebagai berikut.

Dimana:

$$
\mathrm{Y}=\mathrm{a}-\mathrm{b}_{1} \mathrm{X}_{1}+\mathrm{b}_{2} \mathrm{X}_{2}+\mathrm{b}_{3} \mathrm{X}_{3}+\mathrm{b}_{4} \mathrm{X}_{4}+\mathrm{e}
$$

$\mathrm{Y}=$ minat melakukan whistleblowing

$\mathrm{X}_{1}=$ komitmen organisasi

$\mathrm{X}_{2}=$ tingkat keseriusan kecurangan

$\mathrm{X}_{3}=$ personal cost

$\mathrm{X}_{4}=$ sikap

$\mathrm{a}=$ nilai $\mathrm{Y}$ jika $\mathrm{X}=0$ (konstanta)

$\mathrm{b}=$ koefisien linear berganda dari variabel indpenden

$\mathrm{e}=$ error term

\section{Uji Asumsi Klasik}

\section{Uji Normalitas}

Uji normalitas digunakan untuk menguji apakah dalam regresi, variabel pengganggu atau residual memiliki distribusi normal. Pada penelitian ini uji normalitas digunakan dengan metode Kolmogrov-Smirnov dengan melihat angka signifikan 0,05. Jika nilai signifikan yang dihasilkan $>0,05$ maka akan berdistribusi normal.

\section{Uji Multikoliearitas}

Uji multikolineritas menguji apakah ditemukan adanya korelasi antar variabel independen. Untuk menguji adanya multikolinearitas dapat dilihat melauli nilai Varians Inflations Factor $<10$ dan tolerance $>0,1$ apabila terdapat korelasi yang tinggi sesama varibael bebas maka langkah yang harus dilakukan adalah menghilangkan salah satu variabel atau menambahkan variabel bebannya.

\section{Uji Heteroskedastisitas}

IUji heteroskedastisitas bertujuan untuk melihat apakah model regresi terjadi ketidaksamaan variabel dari residual satu pengamatan ke pengamatan lain. Untuk mendeteksi heteroskedastisitas dapat digunakanuji gletser. Apabila sig > 0,05 maka tidak terdapat gejala heteroskedastisitas. Model yang baik adalah yang tidak terjadi heteroskedastisitas. 


\section{Uji Hipotesis}

Uji F

Uji $\mathrm{F}$ menunjukkan apakah semua variabel independen yang dimasukkan kedalam model mempunyai pengaruh secara bersama-sama terhadap variabel dependen. Patokan yang digunakan dengan membandingkan nilai sig lebih kecil dari derajat signifikanmaka persamaan regresi yang diperoleh dapat diandalkan.

\section{Uji Koefisien Determinasi (Adjusted $\boldsymbol{R}^{2}$ )}

Koefisien determinasi (R2) berfungsi untuk melihat sejauhmana keseluruhan variabel independen dapat menjelaskan variabel dependen.

\section{Uji t}

Uji t digunakan untuk mengetahui kemampuan masing-masing variabel independen secara individu (partial) dalam menjelaskan perilaku variabel dependen. Jika nilai signifikan kurang atau sama dengan 0,05 maka hipotesis diterima. Sebaliknya, jika nilai signifikan lebih dari 0,05 maka hipotesis ditolak.

\section{Definisi Operasional}

\section{Minat Melakukan Whistleblowing}

Minat adalah kecendrungan dalam diri individu untuk tertarik pada suatu objek, suatu masalah atau situasi yang mengandung kaitan dengan dirinya. Sedangkan whistleblowing adalah merupakan suatu tindakan yang dilakukan oleh pihak internal maupun eksternal organisasi dengan mengungkapkan kecurangan, kesalhan ataupun prilaku tidak etis yang terjadi pada suatu organisasi.

\section{Komitmen Organisasi}

Komitmen organisasi merupakan suatu komitmen yang diterapkan pada suatu perusahaan dalam pencapaian tujuan perusahaan tersebut. Semakin tinggi tingkat komitmen seorang pegawai maka akan meningkatkan loyalitas pegawai terhadap perusahaan dan akan memberikan feeeback perusahaan.

\section{Tingkat Keseriusan Kecurangan}

Tingkat keseriusan kecurangan merupakan persepsi individu tentang masalah yang ada. Tentang bagaimana individu tersebut meletakkan standar untuk tingkatan permasalahan yang ada. Tingkat keseriusan kecurangan bisa jadi berbeda-beda pada setiap individu.

\section{Personal Cost}

Personal cost didefinisikan sebagai pandangan pegawai terhadap risiko pembalasan/balas dendam atau sanksi dari anggota organisasi, yang dapat mengurangi minat pegawai untuk melaporkan wrongdoing. Personal cost bukan hanya dampak tindakan balas dendam dari pelaku kecurangan, melainkan juga keputudan menjadi pelapor dianggap sebagai tindakan tidak etis, misalnya melaporkan kecurangan atasan dianggap sebagai tindakan yang tidak etis karena menentang atasan. 


\section{Sikap}

Sikap didefinisikan keadaan dalam diri manusia yang berupa perasaan maupun respon untuk mendukung atau memihak maupin tidak mendukung pada suatu objek. Sikapakan menentukan kecendrungan seseorang untuk berprilaku atau bereaksi dengan cara terterntu yang ia yakini.

\section{HASIL DAN PEMBAHASAN \\ Gambaran Umum Objek Penelitian}

Berdasarkan tabel (lampiran), diketahui jumlah kuesioner yang disebar adalah 319 kuesioner dan kuesioner yang dapat diolah sebanyak 146 kuesioner. Jadi, respon rate dalam penelitian ini adalah sebesar $92 \%$.

\section{Statistik Deskriptif}

Berdasarkan tabel 1 dapat dilihat statistik deskriptif dari masing-masing variabel. Pada variable komitmen organisasi diketahui besarnya nilai mean adalah 60,04 dengan standar deviasi 6,001, nilai minimum dan maksimum sebesar 45 dan 72 . Variabel tingkat keseriusan kecurangan diketahui besarnya nilai mean 21,59 dengan standar deviasi 2,218, nilai minimum dan maksimum sebesar 14 dan 25 . Variabel personal cost diketahui besaranya nilai mean 36,94 dengan standar deviasi 4,279, nilai minimum dan maksimum sebesar 26 dan 46. Variabel terakir yaitu sikap diketahui besarnya nilai mean 45,14 dengan standar deviasi 2,986, nilai minimum dan maksimum sebesar 40 dan 57.

Tabel 1

Descriptive Statistics

\begin{tabular}{|l|c|l|l|l|l|}
\hline & N & Minimum & Maximum & Mean & Std. Deviaton \\
\hline Komitmen Organisasi & 146 & 45 & 72 & 60,04 & 6,001 \\
\hline $\begin{array}{l}\text { Tingkat Keseriusan } \\
\text { Kecurangan }\end{array}$ & 146 & 14 & 25 & 21,59 & 2,218 \\
\hline Personal Cost & 146 & 26 & 46 & 36,94 & 4,279 \\
\hline Sikap & 146 & 40 & 57 & 45,14 & 2,986 \\
\hline Whistleblowing & 146 & 15 & 25 & 20,91 & 2,483 \\
\hline Valid N (listwise) & 146 & & & & \\
\hline
\end{tabular}

Sumber : Data primer yang diolah, 2019

\section{Uji Asumsi Klasik}

\section{Uji Normalitas}

Dari hasil pengolahan data SPSS didapat bahwa nilai seluruh variabel dari uji statistik kolmogrov smirnov sebesar 1,047. Berdasarkan hasil tersebut dapat dinyatakan data yang digunakan dalam penelitian ini telah terdistribusi normal dan bisa dilanjutkan untuk diteliti lebih lanjut, karena nilai signifikan dari normalitas sebesar 0,223 >0,05. 
Tabel 2

Uji Normalitas

One-Sample Kolmogorov Smirnov Test

\begin{tabular}{|ll|r|}
\hline & & \multicolumn{2}{|c|}{ Unstandardized } \\
Residual \\
\hline $\mathrm{N}$ & Mean & 146 \\
Normal &, 0000000 \\
Most Extreme & Absolute & 2,27488295 \\
Differences & Positive &, 087 \\
& Negative &, 087 \\
Kolmogorov-Smirnov Z &,- 072 \\
Asymp. Sig. (2-tailed) & 1,047 \\
\end{tabular}

a. Test distribution is Normal

b. Calculated from data

Sumber : Data Primer yang diolah tahun 2019

\section{Uji Mulitikolinearitas}

Berdasarkan tabel 4.14 variabel komitmen organisasi dengan nilai VIF 1,240 dan nilai tolerance sebesar 0,806, variabel tingkat keseriusan kecurangan dengan VIF 1,089 dan nilai tolerance sebesar 0,918, variabel personal cost dengan VIF 1,171 dan nilai tolerance sebesar 0,854, variabel sikap dengan VIF 1,144 dan nilai tolerance sebesar 1,874. Dengan demikian tidak terdapat korelasi variabel-variabel bebas antara satu sama lainnya, atau variabel pada penelitian ini terbebas dari masalah multikolineritas.

Tabel 3

Uji Multikolinearitas

\begin{tabular}{|c|c|c|c|}
\hline \multirow{2}{*}{\multicolumn{2}{|c|}{ Model }} & \multicolumn{2}{c|}{ Collinearity Statistics } \\
\cline { 3 - 4 } \multicolumn{2}{|c|}{} & Tolerance & VIF \\
\hline 1 & Constant) & & \\
\hline & $\begin{array}{c}\text { Komitmen } \\
\text { Organisasi }\end{array}$ & 0,806 & 1,240 \\
\hline & $\begin{array}{c}\text { Tingkat Keseriusan } \\
\text { Kecurangan }\end{array}$ & 0,918 & 1,089 \\
\hline & Personal Cost & 0,854 & 1,171 \\
\hline & Sikap & 0,874 & 1,144 \\
\hline
\end{tabular}

Sumber : Data primer yang diolah, 2019

\section{Uji Heteroskedastisitas}

Berdasarkan tabel 4.15 didapat hasil output yang menunjukkan nilai independen signifikan secara statistik mempengaruhi variabel dependen. Hal ini terlihat dari nilai signifikan diatas tingkat kepercayaan 0,05 atau 5\%. Jadi dapat disimpulkan bahwa model signifikan tidak mengandung adanya heteroskedastisitas dan layak untuk diteliti. 
Tabel 4

\begin{tabular}{|c|c|c|c|c|c|c|}
\hline & & \multicolumn{2}{|c|}{$\begin{array}{l}\text { Unstandardized } \\
\text { Coefficients }\end{array}$} & \multirow{2}{*}{$\begin{array}{c}\text { Standardized } \\
\text { Coeffiecients } \\
\\
\text { Beta } \\
\end{array}$} & \multirow[b]{2}{*}{$\mathrm{T}$} & \multirow[b]{2}{*}{ Sig } \\
\hline \multicolumn{2}{|c|}{ Model } & B & $\begin{array}{l}\text { Std. } \\
\text { Error }\end{array}$ & & & \\
\hline \multirow[t]{5}{*}{1} & (Constant) & 2,947 & 2,046 & & 1,440 & 0,152 \\
\hline & $\mathrm{X}_{1}$ & 0,017 & 0,021 & 0,077 & 1,835 & 0,405 \\
\hline & $\mathrm{X}_{2}$ & $-0,062$ & 0,052 & $-0,103$ & $-1,189$ & 0,236 \\
\hline & $\mathrm{X}_{3}$ & 0,038 & 0,028 & 0,123 & 1,373 & 0,172 \\
\hline & $\mathrm{X}_{4}$ & $-0,049$ & 0,040 & $-0,110$ & $-1,245$ & 0,215 \\
\hline
\end{tabular}

\section{Analisis Data}

Analisis Regresi Berganda

Berdasarkan tabel 5 dapat dilihat model estimasi sebagai berikut.

Tabel 5

Coefficients $^{\text {a }}$

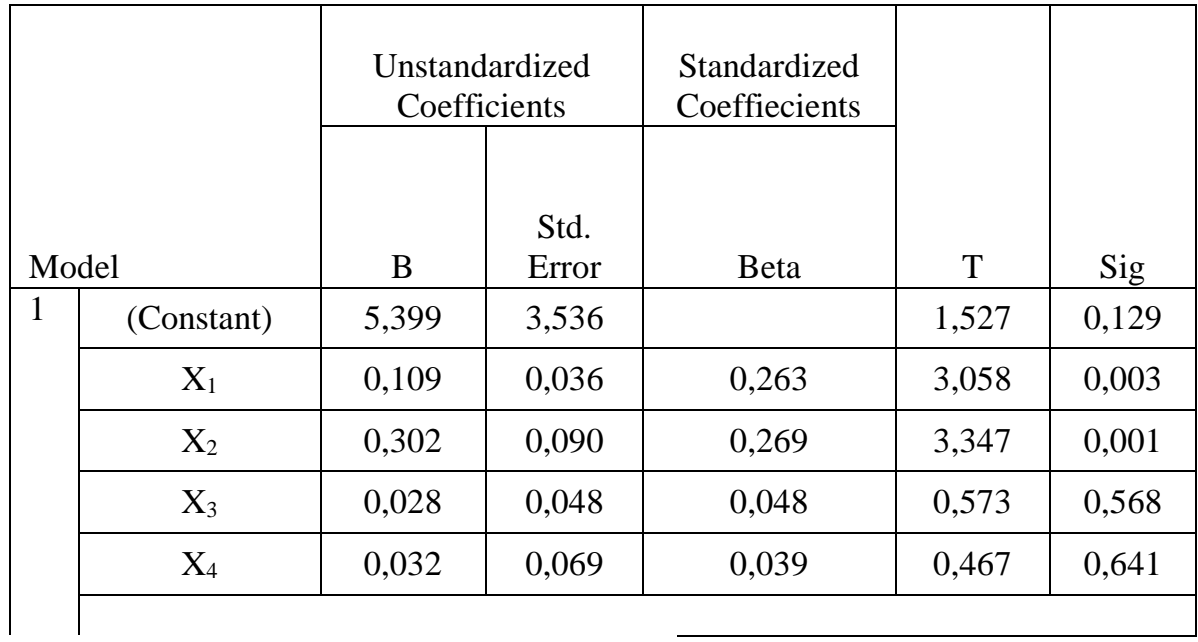

Sumber : Data primer yang diolah, 2019

$$
Y=5,399+0,109 X_{1}+0,302 X_{2}+0,028 X_{3}+0,032 X_{4}
$$

Dimana :

$\mathrm{X}_{1}=$ Komitmen Organisasi

$\mathrm{X}_{2}=$ Tingkat Keseriusan Kecurangan

$\mathrm{X}_{3}=$ Personal Cost

$\mathrm{X}_{4}=$ Sikap

$\mathrm{Y}=$ Whistleblowing 
Dari persamaan diatas, dapat dijelaskan bahwa:

a. Nilai konstanta sebesar 5,399 mengidentifikasi variabel independen yaitu indenpenden yaitu whistleblowing. Jika komitmen organisasi, tingkat keseriusan kecurangan, personal cost, dan sikap bernilai nol, maka nilai whistleblowing adalah sebesar konstanta atau 5,399.

b. Nilai koefisien $\beta$ dari variabel $X_{1}$ bernilai positif yaitu 0,109 . Koefisien komitmen organisasi sebesar 0,109 mengindikasikan bahwa setiap penurunan komitmen organisasi satu satuan akan mengakibatkan peningkatan whistleblowing sebesar 0,109 satuan.

c. Nilai koefisien $\beta$ dari variabel $\mathrm{X}_{2}$ bernilai positif yaitu 0,302 . Koefisien tingkat keseriusan kecurangan sebesar 0,302 mengidentifikasi bahwa setiap peningkatan tingkat keseriusan kecurangan satu satuan akan mengakibatkan peningkatan whistleblowing sebesar 0,302 satuan.

d. Nilai koefisien $\beta$ dari variabel $\mathrm{X}_{3}$ bernilai positif yaitu 0,028 . Koefisien personal cost sebesar 0,028 mengidentifikasi bahwa setiap peningkatan personal costsatu satuan akan mengakibatkan peningkatan whistleblowing sebesar 0,028 satuan.

e. Nilai koefisien $\beta$ dari variabel $\mathrm{X}_{4}$ bernilai positf yaitu 0,032 . Koefisien sikap sebesar 0,032 mengindikasi bahwa setiap penurunan sikap satu satuan akan mengakibatkan penurunanwhistleblowing sebesar 0,032 satuan.

\section{Uji F}

Dari tabel 6 hasil pengolahan data menunjukkan hasil nilai $\mathrm{F}$ sebesar 6.739 dengan signifikan $0,000^{\text {b. }}$ jadi' $F_{\text {hitung }}>F_{\text {tabel }}$ yaitu $6,739>2,44$ dengan nilai signifikansi $0,000 \mathrm{~b}<0,05$. Hal ini menunjukkan bahwa variabel bebas memiliki pengaruh secara bersama-sama terhadap minat melakukan whistleblowing.

Tabel 6

ANNOVA ${ }^{\mathrm{a}}$

\begin{tabular}{|l|l|l|l|l|l|l|}
\hline \multicolumn{2}{|l|}{ Model } & $\begin{array}{l}\text { Sum of } \\
\text { Squares }\end{array}$ & Df & $\begin{array}{l}\text { Mean } \\
\text { Square }\end{array}$ & F & Sig \\
\hline 1 & Regression & 143,454 & 4 & 35,864 & 6,739 & $0,000^{\mathrm{b}}$ \\
\cline { 2 - 8 } & Residual & 750,388 & 141 & 5,322 & & \\
\cline { 2 - 8 } & Total & 893,842 & 145 & & & \\
\hline
\end{tabular}

a. Dependent Variabel: Y

b. Predictors: (Constant), $\mathrm{X}_{1}, \mathrm{X}_{2}, \mathrm{X}_{3}, \mathrm{X}_{4}$

Sumber : Data primer yang diolah, 2019

\section{Adjusted $\boldsymbol{R}^{2}$}

Dari tabel 7 hasil pengolahan data pada adjusted $R$ square menunjukkan nilai 0,160 . Hal ini mengidentifikasi bahwa kontribusi variabel independen dan variabel dependen adalah sebesar $16 \%$, dengan kata lain 16\% whistleblowing dapat dijelaskan oleh variabel bebas. Sedangkan $84 \%$ lainnya ditentukan oleh faktor lain diluar model yang tidak terdekteksi dalam penelitian ini. 
Tabel 7

Adjusted R ${ }^{2}$

Model Summary ${ }^{\mathrm{b}}$

\begin{tabular}{|c|c|c|c|c|}
\hline Model & $\mathrm{R}$ & $\begin{array}{c}\mathrm{R} \\
\text { Square }\end{array}$ & $\begin{array}{c}\text { Adjusted R } \\
\text { Square }\end{array}$ & $\begin{array}{c}\text { Std. Error of the } \\
\text { Estimate }\end{array}$ \\
\hline 1 & $0,401^{\mathrm{a}}$ & 0,160 & 0,137 & 2,307 \\
\hline
\end{tabular}

a. Predictors: (Constant), $\mathrm{X}_{1}, \mathrm{X}_{2}, \mathrm{X}_{3}, \mathrm{X}_{4}$

b. Dependent Variabel: Y

Sumber : Data primer yang diolah, 2019

\section{Uji t}

\section{Pengujian Hipotesis 1}

Dari tabel 4.16 dapat dilihat bahwa komitmen organisasi memiiliki nilai $\mathrm{t}$ hitung $3,058>1,97693 \mathrm{t}$ tabel dan nilai sig $0,000<\alpha(0,05)$ serta nilai koefisien $\beta$ sebesar 0,109 . Hal ini menunjukkan bahwa variabel komitmen organisasi berpengaruh positif terhadap minat melakukan whistleblowing, sehingga dapat disimpulkan bahwa hipoteis 1 diterima.

\section{Pengujian Hipotesis 2}

Dari tabel 4.16 diatas dilihat bahwa tingkat keseriusan kecurangan memiliki nilai $t$ hitung 3.347> $1,97693 \mathrm{t}$ tabel dan nilai sig $0,001<\alpha 0,05$ dengan nilai koefisien $\beta$ sebesar 0,302 . Hal ini menunjukkan bahwa variabel tingkat keseriusan kecurangan berpengaruh positif terhadap minat melakukan whistleblowing, sehingga dapat disimpulkan bahwa hipotesis 2 diterima.

\section{Pengujian Hipotesis 3}

Dari tabel 4.16 dapat dilihat bahwa personal cost memiliki nilai $t_{\text {hitung }} 0,573<t_{\text {table }} 1,97693$ dan nilai sig $0,568>\alpha 0,05$ serta nilai koefisien $\beta 0,028$. Hal ini menunjukkan bahwa variabel personal cost tidak berpengaruh positif terhadap minat melakukan whistleblowing, sehingga dapat disimpulkan bahwa hipotesis 3 ditolak.

\section{Pengujian Hipotesis 4}

Dari tabel 4.16 dapat dilihat bahwa sikap memiliki nilai $t$ hitung $0,467<t_{\text {table }} 1,97693$ dan nilai sig $0,641>0,05$ serta nilai koefisien $\beta 0,032$. Hal ini menunjukkan bahwa variabel sikap tidak berpengaruh positif terhadap minat melakukan whistleblowing, sehingga dapat disimpulkan bahwa hipotesis 4 ditolak.

\section{PEMBAHASAN}

\section{Pengaruh Komitmen Organisasi terhadap Minat melakukan Whistleblowing}

Hasil penelitian ini menunjukkan bahwa komitmen organisasi berpengaruh terhadap minat PNS melakukan tindakan whistleblowing. Hal ini ditunjukkan oleh nilai koefisien regresi $\mathrm{X}_{1}$ bernilai sebesar 0,109 dengan signifikansi sebesar 0,003 lebih kecil dari 0,05,artinya semakin tinggi komitmen organisasi seorang PNS maka semakin tinggi pula minatnya untuk melakukan tindakan whistleblowing.

Hasil penelitian ini sejalan dengan penelitian yang dilakukan oleh Rizki (2014) yang menemukan adanya pengaruh signifikan antara komitmen organisasi dengan niat melakukan tindakan whisteblowing. Namun berbeda dengan penelitian yang dikemukakan oleh MesmerMagnus dan Viswesvaran (2005) yang menunjukan bahwa berdasarkan hasil uji meta analisis, komitmen organisasi tidak memiliki korelasi/keterkaitan dengan minat whistleblowing. 
Wibowo (2015) dalam penelitiannya menjelaskan komitmen organisasi merupakan suatu tingkatan dimana individu mengidentifikasi dan terlibat dengan organisasinya dan/atau ingin meninggalkannya. Rasa peduli terhadap organisasi tersebut adalah cerminan dari konsep komitmen organisasi. Perilaku positif dan sikap akan ditunjukkan seorang karyawan yang berkomitmen terhadap organisasinya (Kuryanto dalam Rizki, 2014). Sehingga jika terdapat fraud (kecurangan) dalam organisasinya yang dianggap suatu hal yang membahayakan organisasi, maka whistleblowing adalah cara seseorang yang memiliki komitmen organisasi untuk melindungi organisasinya dari bahaya kecurangan/fraud tersebut.

\section{Pengaruh Tingkat Keseriusan Kecurangan terhadap Minat Melakukan Whistleblowing}

Hasil penelitian ini menunjukkan bahwa tingkat keseriusan kecurangan berpengaruh terhadap minat PNS melakukan tindakan whistleblowing. Hal ini ditunjukkan oleh nilai koefisien regresi $\mathrm{X}_{2}$ bernilai sebesar 0,302 dengan signifikansi sebesar 0,001 lebih kecil dari 0,05 artinya semakin serius suatu kecurangan yang terjadi maka semakin tinggi pula minat PNS yang mengetahuinya untuk melakukan tindakan whistleblowing. Peningkatan persepsi seseorang mengenai tingkat keseriusan kecurangan dapat mengurangi, mencegah, dan mengatasi kecurangan atau kesalahan yang disengaja yang ada lingkup kerja dengan media whistleblowing.

Hasil penelitian ini mendukung penelitian Resi (2017) dan Menk (2011) yang menjelaskan penelitian ini mengkonfirmasi konsep materialitas tingkat keseriusan kecurangan. Konsep ini digunakan untuk membedakan tingkat keseriusan kecurangan dengan menghasilkan temuan yang sama yaitu berpengaruh positif terhadap niat melakukan whistleblowing, baik secara langsung maupun tidak langsung. Berbeda dengan penelitian yang dilakukan Indri (2016) bahwa tingginya tingkat keseriusan kecurangan tidak akan mempengaruhi seseorang untuk melakukan tindakan whistleblowing. Salah satu alasannya dikarenakan tingkat pendidikan dan masa kerja responden yang relatif rendah. Sehingga pengalaman yang dimiliki rendah.

\section{Pengaruh Personal Cost terhadap Minat Melakukan Whistleblowing}

Berdasarkan hasil pengujian hipotesi ketiga, menunjukkan bahwa personal cost tidak berpengaruh terhadap minat PNS melakukan tindakan whistleblowing. Hal ini ditunjukkan oleh nilai koefisien regresi $\mathrm{X}_{3}$ bernilai sebesar 0,028 dengan signifikansi sebesar 0,568 lebih besar dari 0,05 artinya bahwa variabel personal cost tidak mampu menjadi faktor yang menjelaskan minat seorang PNS untuk melakukan whistleblowing.

Penelitian ini sejalan dengan temuan penelitian yang dilakukan oleh Rizki (2014) dan Resi (2017) dimana tidak berpengaruhnya personal cost terhadap minat seorang untuk melakukan whistleblowing menunjukkan bahwa adanya kemungkinan responden telah dapat mengelola/menghindari risiko pembalasan atau sanksi dari anggota organisasi pada saat melakukan whistleblowing. Sejalan dengan penelitian Rizki (2014), tidak berpengaruhnya personal cost atas temuan peneliti ini dapat disebabkan karena responden telah familiar dengan hal-hal yang berkaitan dengan kecurangan sehingga tidak mementingkan resiko personal cost tersebut.

\section{Pengaruh Sikap terhadap Minat Melakukan Whistleblowing}

Berdasarkan hasil pengujian hipotesis terakhir, menunjukkan bahwa variabel sikap tidak berpengaruh terhadap minat PNS melakukan tindakan whistleblowing. Hal ini ditunjukkan oleh nilai koefisien regresi $\mathrm{X}_{4}$ bernilai sebesar 0,032 dengan signifikansi sebesar 0,641 lebih besar 
dari 0,05 artinya bahwa variabel sikap tidak mampu menjadi faktor yang menjelaskan minat seorang PNS untuk melakukan whistleblowing.

Hasil penelitian ini sejalan dengan penelitian Aliyah (2016) dimana hasilnya pengujian hipotesisnya secara statistik menunjukkan variabel sikap tidak berpengaruh terhadap minat melakukan tindakan whistleblowing. Menandakan bahwa hasil pengujian ini tidak sesuai dengan Theory of Planned Behaviour(Ajzen, 1991) yang mengungkapkan bahwa sikap seseorang terhadap suatu tindakan bergantung pada keyakinan akan ada atau tidaknya dampak/konsekuensi yang dihasilkannya. Secara logis kecendrungan sikap untuk mendukung tindakan whistleblowing akan meningkatkan minat seseorang untuk melakukannya. Sehingga bila ditafsirkan semakin kecil kecendrungan sikap seorang PNS untuk mendukung whistleblowing maka semakin kecil pula minatnya untuk melakukan whistleblowing, begitupun sebaliknya.

\section{KESIMPULAN, KETERBATASN DAN SARAN \\ Kesimpulan}

Berdasarkan hasil penelitian dan pengujin hipotesis yang telah dilaksanakan, maka hasil penelitian dapat disimpulkan sebagai berikut:

1. Komitmen organisasi berpengaruh positif terhadap minat PNS melakukan tindakan whistleblowing

2. Tingkat keseriusan kecurangan berpengaruh positif terhadap minat PNS melakukan tindakan whistleblowing.

3. Personal cost tidak berpengaruh positif terhadap minat PNS melakukan tindakan whistleblowing

4. Sikap terhadap whistleblowing tidak berpengaruh positif terhadap minat PNS melakukan tindakan whistleblowing

\section{Keterbatasan Peneleitian}

Meskipun penelitian telah berusaha merancang dan mengembangkan penelitian sedemikian rupa, namun masih terdapat beberapa keterbatasan dalam penelitian ini, diantaranya :

1. Subjek yang menjadi sampel dalam penelitian ini hanya PNS disatu universitas, sehingga model regresi yang dihasilkan belum tentu sesuai untuk digeneralisasi/digunakan pada PNS di universitas lainnya yang mungkin memiliki karakteristik personal dan pengaruh budaya organisasi yang berbeda.

2. Waktu pelaksanaan penelitian ini yang sering bertepatan dengan rapat yang diadakan dari instansi tempat penelitian. Sehingga responden terlalu sibuk untuk mengisi kuesionar dan menyebabkan banyak kuesioner yang tidak kembali dan tidak diisi, serta waktu pelaksanaan penelitian yang lama.

3. Pendekatan kasus cerita variabel tingkat keseriusan kecurangan pada kuesioner yang lumayan panjang memungkinkan responden malas untuk membaca kasus tersebut.

\section{Saran}

Adapun saran yang mungkin berguna untuk penelitian selanjutnya adalah sebagai berikut:

1. Menguji kembali konsistensi pengaruh faktor personal cost dan sikap terhadap minat whistleblowing dan bila perlu mengkaji ulang definisi personal cost dan sikap yang sesuai dengan kondisi di Indonesia.

2. Pada penelitian ini memiliki $\mathrm{R}^{2}$ yang rendah yang berarti masih terdapat faktor lainnya yang dapat mempengaruhi minat seseorang untuk melakukan whistleblowing. Karena itu peneliti 
selanjutnya dapat meneliti faktor-faktor lain yang dapat mempengaruhi minat PNS untuk melakukan whistleblowing.

3. Melakukan penelitian dengan menggunakan sampel yang lebih luas seperti penambahan sampel di berbagai universitas yang mewakili PNS di Indonesia.

\section{DAFTAR PUSTAKA}

ACFE (Association of Certified Fraud Examiners) Indonesia. (2018). Survai Fraud Indonesia chapter \#111. ACFE Indonesia Chapter: Jakarta.

Alleyne, P., M. Hudaib, dan R. Pike. (2013). Towards a Conceptual Model of Whistleblowing Intention Among External Audtiors.The British Accounting Review, 45: 10-23.

Ajzen, I. (1991). The theory of planned behavior. Organizational Behavior and Human Decision Prosess, 50 (2).

Badan Pemeriksa Keuangan Republik Indonesia. (2014). Ikhtisar Hasil Pemeriksaan Semester (IHPS) I Tahun 2019. Jakarta.

Bagustianto, R dan Nurkholis. 2014. Faktor-Faktor Yang Mempengaruhi Minat Pegawai Negeri Sipil Untuk Melakukan Tindakan Whistleblowing (studi pada PNS BPK RI). Malang: Universitas Brawijaya.

Bouville, M. (2007). Whistle-Blowing and Morality. Journal of Business Ethics. 2008 (81); 579585.

Jalil, F., Y. 2014. Pengaruh Komitmen Profesional dan Antisipati Mahasiswa Audit terhadap Perilaku Whistleblowing. Jakarta: Universitas Islam Negeri Syarif Hidayatullah.

Ghozali, Imam dan A. Chariri. (2007). Teori Akuntansi, Badan Penerbit Univ Diponegoro, Semarang.

Ghozali, I. (2007). Aplikasi Analisis Multivarite dengan SPSS. Semarang: Univesitas Diponegoro.

Gujarati, D., N. (2006). Ekonometrika Dasar. Jakarta: Erlangga

Humaira, N. 2017. Pengaruh Faktor Individual dan Situasional terhadap Intensi Pegawai Negeri Sipil untuk Melakukan Tindakan Whistleblowing Internal". Semarang: Universitas Diponegoro.

James L, Gibson, et al., (2012). Organization: Behaviour, Structure, Processes. $14^{\text {th }}$ Edition. New York: McGraw-Hill Companies, Inc

KNKG. Pedoman Sistem Pelaporan Pelanggaran - SPP (Whistleblowing System -WBS). Jakarta: KNKG.

Lestari, R dan Rizal,. Y. (2017). Whistleblowing dan Faktor-faktor yang Memengaruhi Niat Melaksanakan oleh Aparatur Negara. Yogyakarta: Universitas Muhammadiyah Yogyakarta.

Lewis, D. 2008. Ten years of public interest disclosures in the U.K: Are whistleblowers adequately protected? Journal of Business Ethics. 82, 497-507

Malik M.G., \& Rahardian. 2010. Analisis Perbedaan Komitmen Profesional dan Sosialisasi Antisipatif Mahasiswa PPA dan Non-PPA Pada Hubungan Dengan Whistleblowing (Studi Kasus Pada Mahasiswa Akuntansi Universitas Diponegoro). Semarang: Universitas Diponegoro.

Marliza, R. (2017). Pengaruh Personal Cost of Reporting. Komitmen Organisasi dan Tingkat Keseriusan Kecurangan terhadap Niat Melakukan Whistleblowing. Padang: Universitas Negeri Padang. 
Menk, Karl Bryan. (2011). The Impact of Materiality, Personality Traits, and Ethical Position on Whistleblowing Intentions. VCU Scholars Compas Journal.

Mesmer-Magnus, J. R. dan C. Viswesvaran. (2005). Whistleblowing in Organizations: An Examination of Correlates of Whistleblowing Intentions, Actions, and Retaliation. Journal of Business Ethics, 62 (3), 277-297.

Mowday, R. T., Steers, R. M., dan Porter, L. W. (1979) The measurement of Organizational Commitment. Journal of vocational behavior, 14(2), 224-247.

Putra, A., F. 2015. Pengaruh Faktor Individual dan Situasional terhadap Niat Melakukan Whistleblowing. Yogyakarta: Universitas Gadjah Mada.

Park, H. dan J. Blenkinsopp. (2009). Whistle-blowing as planned behavior - a survey of South Korean police officers. Journal of Business Ethics, 85(4), 545-556.

Rustiarini, Ni Wayand dan Sunarsih N., M. 2015. Fraud dan Whistleblowing: Pengungkapan Kecurangan Akuntansi oleh Auditor Pemerintah. Denpasar: Universitas Mahasaraswati Denpasar.

Sabang, Muh Iskandar, (2013). "Kecurangan, Status Pelaku Kecurangan, Interaksi IndividuKelompok, dan Minat Menjadi Whistleblower (Eksperimen pada Auditor Internal Pemerintah. Tesis)". Malang: Fakultas Ekonomi dan Bisnis Universitas Brawijaya.

Sari, Riri Permata. 2018. Faktor-faktor yang mempengaruhi Pegawai Negeri Sipil untuk Melakukan Tindakan Whistleblowing. Padang: Universitas Negeri Padang.

Samudra, Nurul Hidayati. (2014). "Persepsi Mahasiswa terhadap Tindakan Whistleblowing". Semarang: Universitas Dian Nuswantoro Semarang.

Saud, Ilham Maulana. (2016). "Pengaruh Sikap dan Pesepsi Kontrol Perilaku terhadap Niat Whistleblowing Internal-Eksternal dengan Persepsi Dukungan Organisasi Sebagai Variabel Pemoderasi”. Yogyakarta: Universitas Muhammadiyah Yogyakarta.

Schultz, J., Johnson, D., Morris, D., \&Dyrnes, S (1993). An investigation the reporting of questionable acts in an international setting. Journal of Accounting Research, 31(1), 75103.

Sweeney, P. 2008. Hotlines Helpful for Blowing the Whistle. FinancialExecutive. 24 (4); 28 31.

Sugiyono. (2013). "Metode Penelitian Bisnis (Pendekatan Kuantitatif, Kualitatif, dan R\&D)". Bandung: Alfabeta.

Taylor, E. Z., dan Curtis, M. B. (2010). An Examination of the Layers of Workplace Influences in Ethical Judgments: Whistleblowing Likelihood and Perseverance in Public Accounting. Journal of Business Ethics 92: 21-37.

Wells, J. T. (2007). Corporate Fraud Handbook: Prevention and Detection: Second Edition. John Wiley andSons Inc.

Winardi, Rijadh Djatu. (2013). The Influence of Individual and Situational Factors on LowerLevel Civil Servants ${ }^{e}$ Whistle-Blowing Intention in Indonesia. Journal of Indonesian Economy and Business. 28 (3); 361-376.

Wibowo, I Gede Putro. (2015). "Pengaruh Stres Kerja Terhadap Kepuasan Kerja dan Komitmen E-journal Ekonomi dan Bisnis Universitas Udayana”. 4.02.PP: 125-145..

Wulandari, Indri. (2016). "Pengaruh Personal Cost of Reporting, Komitmen Profesional, dan Tingkat Keseriusan Masalah terhadap Whistleblowing”. Padang: Universitas Negeri Padang. 